\title{
Current Status and Future Trends in Protection, Control and Communications Testing in Electrical Grids using Real-time Simulation
}

\author{
Eduardo Gómez Luna ${ }^{1}$ John Edwin Candelo Becerra ${ }^{2}$ and Eduardo Marlés Sáenz ${ }^{3}$ \\ ${ }^{1}$ Potencia y Tecnologías Incorporadas S.A Grupo de Investigación, GITICAP Cra. 56 No. 2-50. Avenida Guadalupe. Cali, Colombia \\ ${ }^{2}$ Universidad Nacional de Colombia, Sede Medellín Departamento de Energía Eléctrica y Automática Facultad de Minas Grupo de \\ Investigación en Tecnologías Aplicadas Carrera 80 No. 65-223, Medellín, Colombia \\ ${ }^{3}$ Universidad del Valle Escuela de Ingeniería, Eléctrica y Electrónica Facultad de Ingeniería Grupo de Investigación en Alta Tensión \\ Gralta Carrera 13 No. 100-00, Cali, Colombia
}

Received 5 May 2018; Accepted 15 October 2018

\begin{abstract}
In recent times, real-time simulation has been used to validate the testing and design of protection, control, and communications systems prior to their commissioning in the field, which has improved the reliability and security of the commissioning processes for electrical systems. This paper reviews the state-of-the-art and future trends in protection, control, and communications testing of electrical grids using real-time simulation. In addition, a summary is presented in which all the works and technologies mentioned are listed with the purpose of identifying new challenges in the proposed topic. Finally, future trends related to the use of real-time simulation for evaluating protection, control, and communications schemes are presented. Real-time simulation is very useful due to the increasing complexity of modern electrical power systems, therefore, it is necessary to use this kind of tool to facilitate field testing, avoid unnecessary work, and reduce costs for clients.
\end{abstract}

Keywords: Real-time simulation hardware in the loop, software in the loop, protection relay, control test

\section{Introduction}

Simulations have been used for many years for the planning and design of electrical networks [1], from the incorporation of transmission lines in power systems to the optimization of motor drives in the transportation sector. Simulations have performed a fundamental role in the development of a great many applications [2]. During the last decades, the evolution of simulation tools has been carried forward by the accelerated evolution of computational technologies. Because computational technologies have improved their performance, the capacity of the simulation tools for solving large and complex problems has also increased in a short time [3]. Additionally, the cost of digital simulators is decreasing constantly, making them available and accessible to a great number of users for many applications $[4,5]$.

Real-time simulation is a process whose purpose is to reproduce, with the highest possible level of precision, the dynamics and response times of real systems through the use of computing hardware and software. This allows the evaluation of complete electrical systems with their respective protection, control, and communications schemes and makes it possible to observe their performance as though they were implemented in real systems [6].

Recent advances in computing have allowed the rapid development of real-time simulation in many applications, including the testing of protection, control, and communications equipment in electrical systems.

*E-mail address: eduardo.gomez@pti-sa.com.co

ISSN: 1791-2377 @ 2018 Eastern Macedonia and Thrace Institute of Technology. All rights reserved.

doi:10.25103/iestr.114.25
On the other hand, the efficient operation of electrical grids is a great challenge for the electrical sector as they constitute highly complex systems. Such systems involve a large number of devices, where the integration of each one should maintain the equilibrium of the properly operating system [7, 8]. Thus, it is of great importance to carry out factory and on-site integral tests of different equipment and elements that make up an electrical grid in such a way that the correct operation of the system can be checked [9].

With the emergence of new fields of application, powerful real-time simulators, and novel procedures introduced by modern engineering, the optimization of traditional testing and commissioning processes of electrical schemes and equipment has been achieved [10]. Various reference institutions for the electrical sector have proposed to modernize, optimize, and include in the processes the participation of information and communication technologies as a means to integrate all system domains and a catalyst of the advantages that these technologies represent [11] in relation to reliability, quality, and efficiency improvements in the service. This has been evidenced in the works referenced below, where real-time simulators, information technologies, and telecommunications have been used to optimize the testing and commissioning processes [10], [12-21].

The incorporation of real-time technology prior to implementation provides relevant support to the protection and control tests of electrical grids. At the same time, it allows reducing the costs and maintenance time, avoiding unnecessary engineering, and increasing the reliability of the energy supply. The implementation of this technology will allow electricity companies to make fast and timely 
decisions at the time of carrying out any kind of reconfiguration of electrical schemes and power system equipment.

\section{Protection, Control and Communications Testing Using Real-Time Simulation}

\subsection{Protection systems}

In large transmission and distribution electrical grids, electrical substations are commonly monitored and controlled [22, 23]. However, when the start-up test of the different elements are performed, for example the ones corresponding to a substation, a group of inspections should be done at the time of manufacture, before energizing the elements and after putting them into service [24, 25].

Protection schemes vary from one electrical system to another, depending on the voltage levels, importance of the installation, and the energy company. Such schemes are classified according to the importance of the machines or equipment to be protected, such as generators, transformers, capacitor banks, buses, and lines [23, 26].

Advances in electrical grid protection have been considerable due to the recent integration with microprocessor technologies, which allows a single protection unit to include many different functions $[27,28]$. Thus, the integration of functions is convenient when they complement each other to avoid power system faults.

Nowadays, technology allows to integrate both protection and control functions, where it is possible to have equal and redundant units for each output and that seems to have economic appeal based on the fact that the time and number of operation contacts are not compromised [6, 23, 28].

\subsection{Control and communications systems}

Currently, two control concepts prevail in electrical grids - traditional and automated-with the latter being the trend in modern electrical grids. The use of intelligent electronic devices (IEDs), which are autonomous apparatuses with integration and communication capacities, through standard protocols that make use of one or more microprocessors with the ability to send and receive information [6, 22, 27].

Some automatic maneuvering concepts in control systems are based fundamentally on available information inside the substation, where the action of the control devices may be sent or modified in a local or remote way. Some automated operations in electrical grids are relay automatic setup, automatic maneuvering of equipment, automatic reclosing, synchronized control of switches, transformer control, low-frequency automatic disconnection of load, automatic system restoration after a loss of power supply, sectionalization of the fault zone, automatic control of tap changers, and reactive power control as mentioned in $[22,23$, $27,28]$.

\subsection{Protection, control, and communications test}

In protection and control, each device and instrument must be completely assembled, set up, and tested in the factory, which is commonly known as Factory Acceptance Testing (FAT). Later, these devices must be subjected to tests to ensure reliable operation of all the components in the field, known as Site Acceptance Testing (SAT).

FAT guarantees the security and quality of the equipment, device, or instrument before its delivery or final installation. It is necessary to be sure that equipment is operating properly and without anomalies that can affect the in-field functionality and installation. With these tests, it is possible to check that all specifications and previously established requirements have been met $[24,25,29,30]$.

SAT makes it possible to determine the electrical, mechanical, operational, and environmental characteristics of each electrical component under real operating conditions, with the aim of guaranteeing the fulfillment of the design specifications. The results obtained through this test are able to establish parameters that make it possible to determine the degree of degradation and allow early detection of malfunctions in the system or equipment during their normal operation and lifetime in the electrical grid $[23,31]$.

Fig. 1(a) displays a scheme representing the current method of protection, control, and communications tests performed on electrical grids. Traditional FAT is applied to each individual component, which entails manual and disjointed work, that is, it does not involve the integration of all the equipment making up the system to evaluate the performance and interactions among them. To develop traditional FAT, three-phase injection equipment is used, which makes it possible to obtain current and voltage magnitudes and other magnitudes with high precision, however, this technique incurs high costs in terms of equipment and availability. In addition, when performance tests are carried out through simulations, they are performed in a decoupled manner and not in real time, i.e., offline. Thus, there is no mathematical, functional, or precise model representation of the power environment that the system is going to face as it does not represent a real plant.

In Fig. 1(a), it can be observed that to test the protection, control, and communications schemes in $n$ bays, the use of $n$ injection devices is indispensable. This is not efficient from an operational, logistical, or economic point of view due to factors that carry weight at the time of test execution such as the necessary staff coordination, time, and availability of the testing equipment. When commissioning tests are carried out in the traditional manner, the following questions are posed: To which bay are the tests applied? To which breakers are the tests applied? What happens to the other protection, control, and communications devices in the substation? Is there a model of the system? Finally, is there synchronism in test execution?

The optimization of integral protection, control, and communications in electric grids using real-time simulation, information technologies, and telecommunications, as shown in Fig. 1(b), makes it possible to save time and achieve testing precision and optimal and efficient designs in view of demanding and modern power systems and electrical grids.

In Fig. 1(b), the process of implementation of the necessary technologies to simulate an electrical grid in real time-in this case, as an example, a substation and its protection equipment- - has been divided into three stages:

- Stage 1: Base technologies for modeling and visualization.

- Stage 2: Processing, data flow, and communications.

- Stage 3: Integration schemes, signal acquisition, and performance monitoring.

The first stage refers to the selection of the software platform and technologies for modeling and performance visualization of the system under analysis. In the current market, there are several companies that offer interesting solutions in real time. The second stage of implementation 
encompasses the processing hardware components, data flow, and communications. In this stage, the necessary equipment and processing power to carry out the real-time computations, data flow to and from the simulation hardware, and finally the technologies and protocols of communications to connect the simulation workstations with external protection, control, and communications devices are established according to the test requirements.

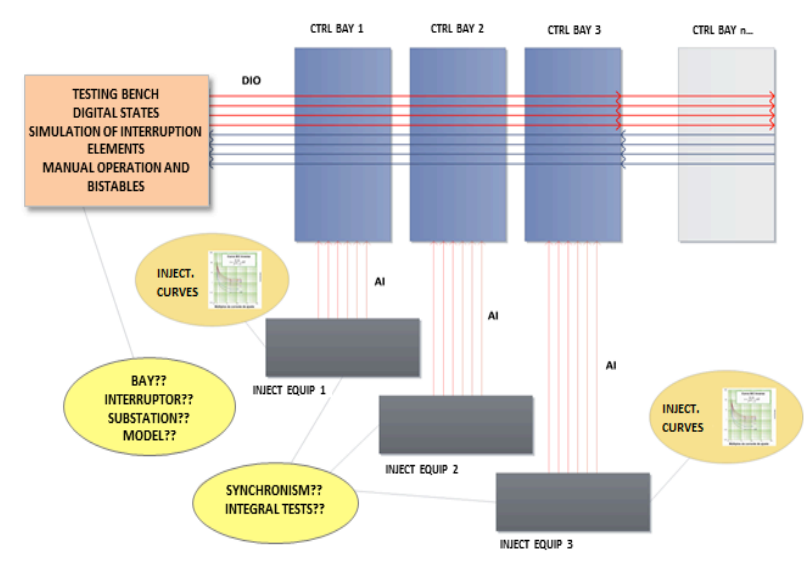

(a)

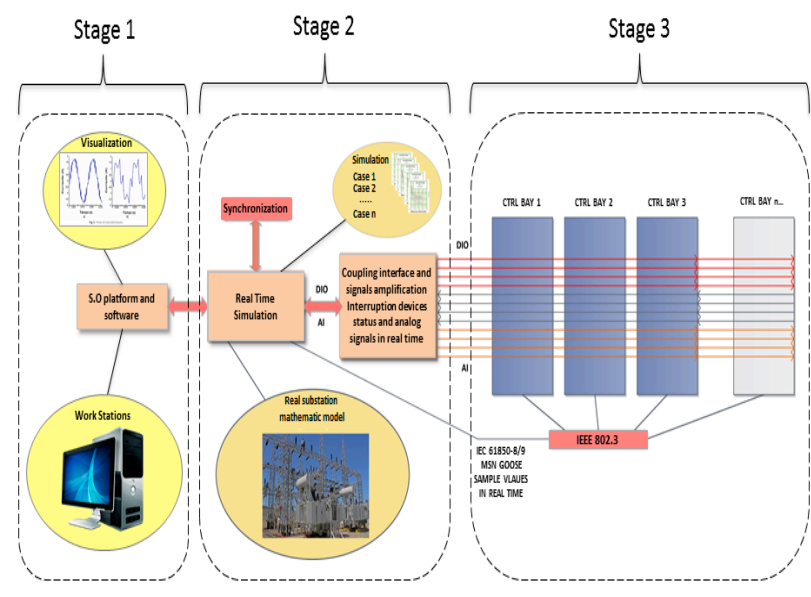

(b)

Fig. 1 Protection, control, and communications testing: a) Traditional way and b) Using RTS

The third stage of implementation is related to the schemes and technologies that interact with the power equipment. This corresponds to signal amplification, data acquisition devices, monitoring technologies, and operation schemes to carry out a real-time simulation loop.

These implementation stages promote the development and use of real-time simulation, information technologies, and telecommunications. This makes it possible to integrate the real functionality of protection, control, and communications equipment with a precise simulation of the real power system through effective interfaces for the respective data exchange in a quick, secure, and reliable way.

2.4 Real-time simulation for protection, control, and communications schemes

Different schemes that use real-time simulation for the commissioning of protection, control, and communications systems in electrical grids have been developed, currently, there are four main representative schemes into which the different techniques and methodologies to carry out real-time electrical performance tests can be grouped. These schemes are software in the loop (SIL) or model in the loop (MIL), rapid control prototyping (RCP) or controllers in the loop (CIL), hardware in the loop (HIL), and finally power hardware in the loop (PHIL). These schemes are widely used for the representation and modeling of electrical systems and protection, control, and communications schemes with the aim of obtaining a preview of what the real system performance could be.

\subsubsection{Software in the Loop (SIL) or model in the Loop (MIL)}

In an SIL scheme, both the controller and plant may be simulated in real time (Fig. 2) [32]. This is very useful when it is difficult to access protection, control, and communications systems. However, all the devices must have the validated models to obtain accurate results [33].

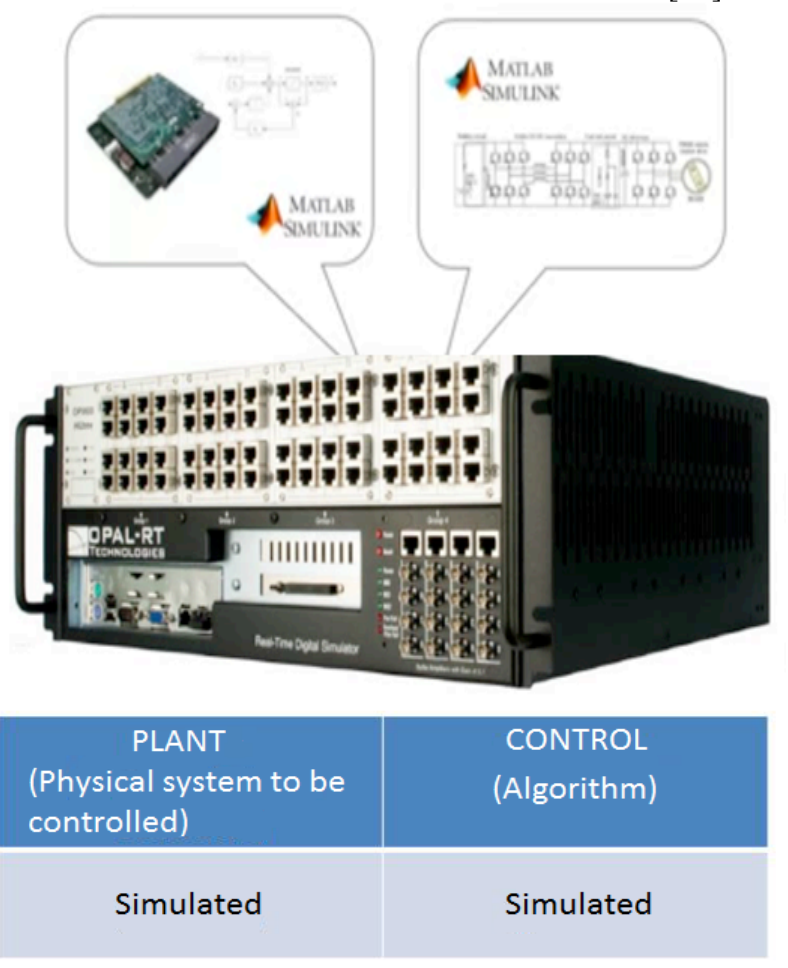

Fig. 1. SIL scheme

\subsubsection{Rapid Control Prototyping (RCP)}

In an RCP scheme or CIL (controllers in the loop) scheme, the plant is real and the controller is simulated. The plant is connected through an input/output interface to the virtual controller. The control implemented through a real-time simulator has the advantages of being faster, more flexible, and easy to program [34]. Due to these characteristics, it is very useful in the optimization of algorithms for the control, validation, and detection of errors (Fig. 3).

\subsubsection{Hardware in the Loop (HIL)}

An HIL scheme involves the simulation of a virtual plant [35] in such a way that its implementation with the real controllers is possible through an input/output interface (Fig. 4). Some implementations based on this concept can be reviewed in [36-47]. Other references related to this scheme can be found in Table I. 
Eduardo Gómez Luna, John Edwin Candelo Becerra and Eduardo Marlés Sáenz/

Journal of Engineering Science and Technology Review 11 (4) (2018) 204 - 215
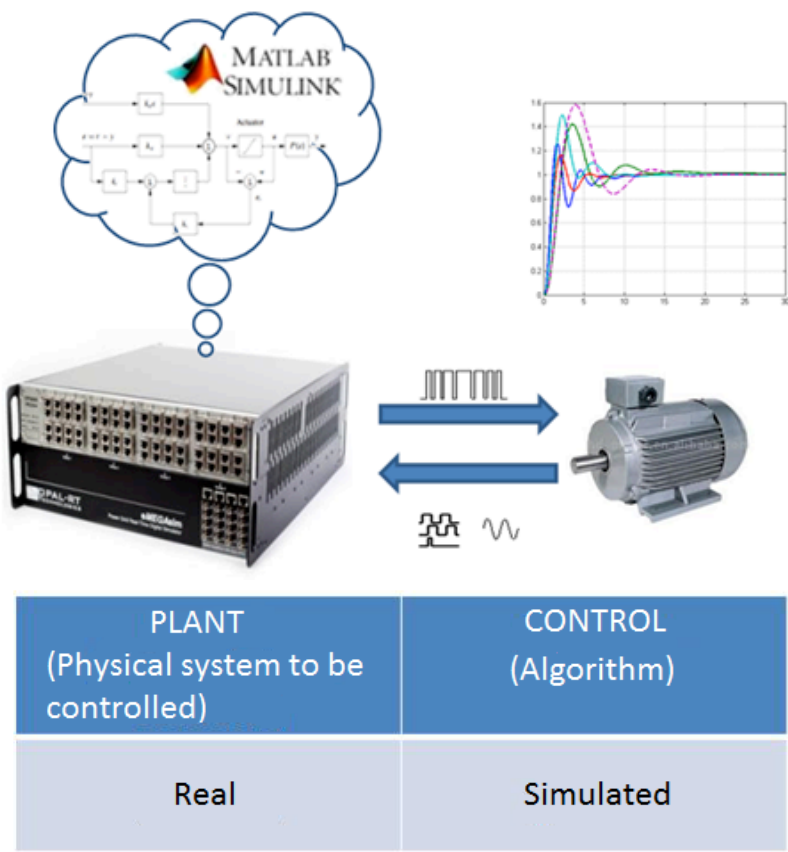

Fig. 2. RCP scheme

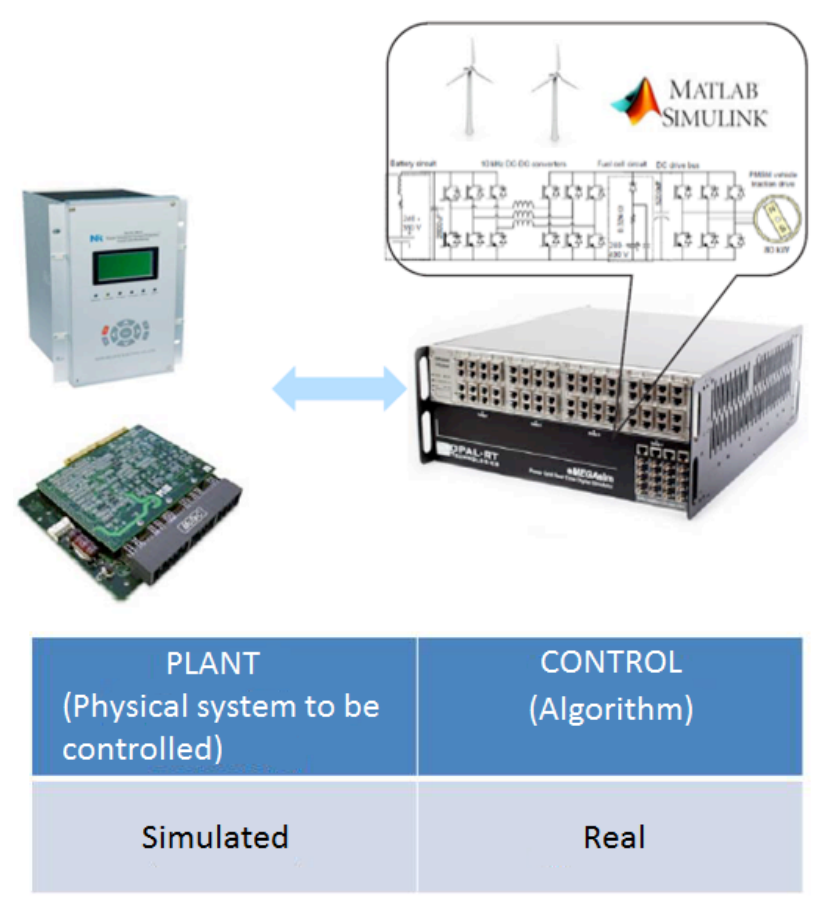

Fig. 3 HIL scheme

\subsubsection{Power Hardware in the Loop (PHIL)}

A PHIL scheme comprises a complete integration of a power system with its voltage and current signals equal to those in a real system (Fig. 5). The PHIL concept is essentially an extension of the HIL functionality and is based on the interaction of components or elements that require high power flows, and with an electric circuit or grid running on a simulator [48, 49]. Figs. 5 and 6 illustrate the operation and functionality of a PHIL scheme, where the conditions and topology of the grid, as well as the occurrence of faults, contingencies, and abnormal operation, are simulated through real-time simulation. The interface with the protection, control, and communications equipment, such as relays, is made through power amplifiers whose function is to amplify the small signals delivered by the real-time simulator to an adequate magnitude so that the relays can operate (secondary injection) as shown in $[17,19,47$, 49-53]. Schemes similar to PHIL can be reviewed in [17, 47, 49-51, 54], where their implementation and performance evaluation are described in great detail. Other references related to this scheme can be found in Table I.

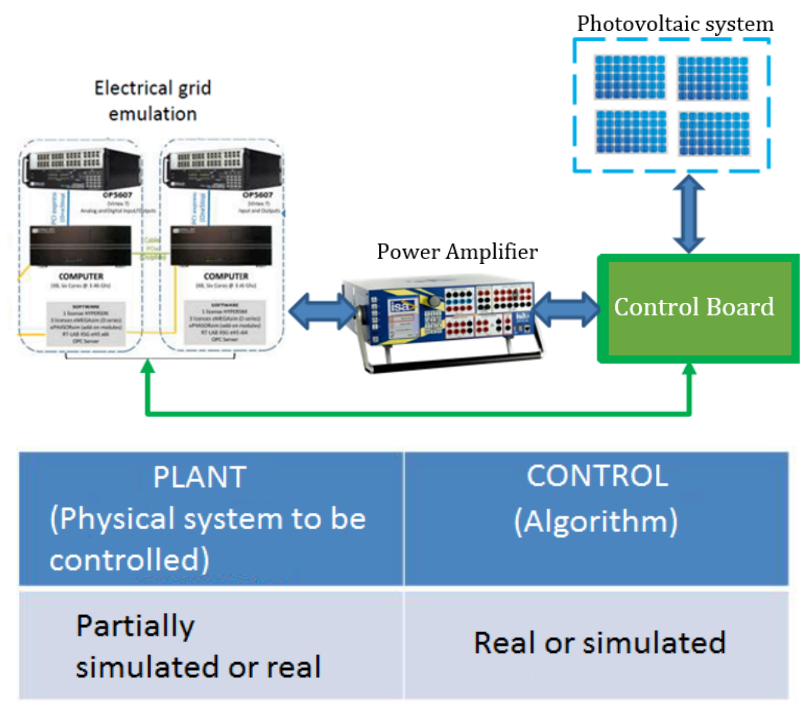

Fig. 4. PHIL scheme

In relation to hardware and real-time simulation computing power, companies like OPAL-RT Technologies, RTDS, DSpace, Speedgoat, and National Instruments have an important place on the market due to the interesting range of solutions they offer. However, just a few of them have dedicated lines and technologies focused on real-time simulations of power systems or, importantly, on the implementation of solutions that allow the testing of system and protection devices through HIL and PHIL integration schemes.

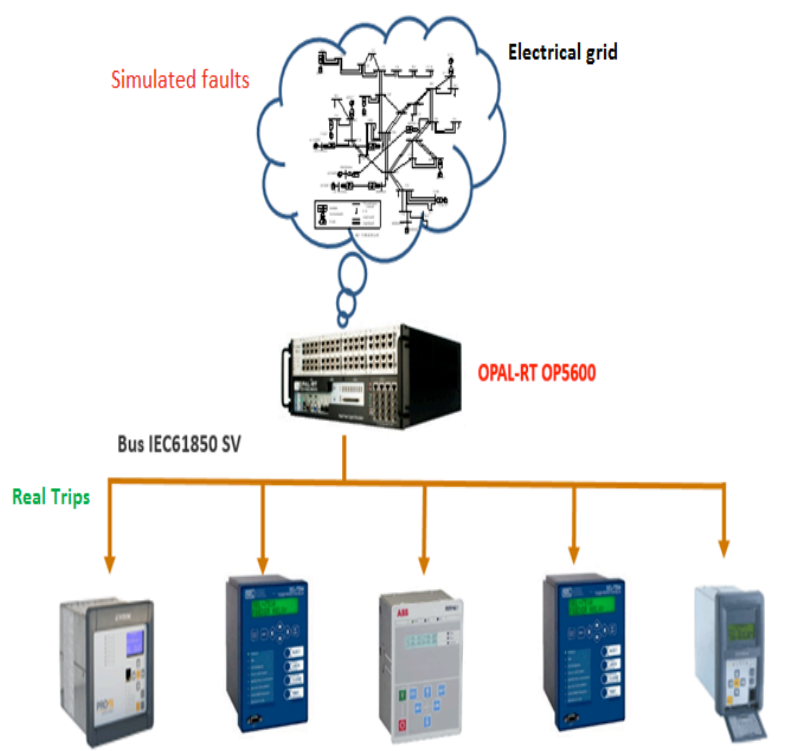

Fig. 5 Real-time simulation integration with real protection equipment (PHIL)

In this way, OPAL-RT Technologies and RTDS are companies that currently lead the market in real-time simulators, offering hardware and software solutions to carry out modeling, simulation, and visualization of real-time performance of an electrical grid, following any of the 
previous real-time schemes mentioned.

On the other hand, Mathwork's flagship software, MATLAB, does not fall behind in the incorporation of toolboxes and software solutions for real-time simulation in what is named MATLAB Real-Time Workshop. Experiences of using OPAL-RT Technologies can be reviewed in considerable detail in $[41-47,55,56]$ while RTDS can be reviewed in [19, 53, 57-66] and MATLAB Real-Time Workshop can be reviewed in [37, 40, 59, 67, 68] Other references related to this scheme can be found in Table I.

Advances in ICT are playing a key role in the development of real-time simulation technologies. With the incorporation of standards and protocols of communication, data management, and control, such as IEC $61850[17,19$, $36,49,51,69,70]$, IEC $61970[69,71]$, and DNP3 [17, 38, $47,49,60,72,73]$, applications that previously needed equipment and devices to be close to each other due to connectivity and data acquisition requirements are no longer subject to this limitation. Using Ethernet and WLAN networks through the protocols as mentioned, it is possible to integrate, simulate, and monitor in real time the performance and behavior of protection, control, and communications equipment and devices that comprise the real electrical grid. In this way, it is possible to obtain a precise reproduction of the system and to test it over different operating conditions established by engineers and all from centralized or unified workstations, called "WAMPAC" [36, 37, 40, 41, 49, 69] or "CPCS" [70, 74-76].

The development of measurement and monitoring devices such as Phasor Measurement Units (PMUs) and intelligent electronic devices (IEDs) for control and management, which essentially allow the monitoring, control, and management of electrical grids, provides a step toward the goal of achieving real electrical systems behavior Significant work is being conducted in regard to the functionality of these devices when integrated with real-time simulation with the aim of sampling and reproducing the performance of an electrical grid. Reports on development projects using these kinds of devices are available in $[17,43$, $47,60,77]$ and $[19,28,36,49,69,70,72]$ in relation to PMUs and IEDs, respectively.

Table I presents references related to real-time simulation implementation stages for protection, control, and communications testing. Additional references to journals and papers where the reader can find detailed information about the mentioned technologies are also cited in this table $[55]$.

\section{Real-time Simulation Challenges and New Trends for Protection, Control, And Communications Testing}

Computing technologies have improved dramatically in recent years in terms of execution and cost and time savings. Usually, offline simulations are insufficient to reproduce the behavior of closed-loop systems with the integrated control software and real hardware to reach the required precision, thus, there is a need for real-time simulation.

Real-time simulation is the key to managing the complexity of modern electrical systems, as it allows to compensate the limitations of offline testing, while reproducing the complexity of protection, control, and communications schemes. This solution allows advantages such as flexibility, fast commissioning, easy data depuration, and wide range of tests.

In relation to the electrical grid's communications systems, there is substation automation based on the IEC61850 standard, which is in the process of being accepted around the world for the implementation of intelligent grids in energy transmission and distribution systems. The optimal design for the integration of primary and secondary systems undoubtedly improves the control performance of substations and reduces wiring and maintenance.

Real-time simulation is used for closed loop testing of protection, control, and communications solutions. When conducting closed-loop testing, the simulator acts as the power system and interfaces to the test objects. For closed-loop operation protective relay testing, the simulator must provide real time data to the relay and sense trip and reclose status from the relay. Because the power system is being simulated, various faults can easily be applied under different network conditions to evaluate the performance of the protection, control, and communications. If the protection detects a fault, the trip signal will be sensed and the breaker in the simulation opened. On the other hand, with the real time simulation it is possible to try the interoperability between many different IEDs.

In the fields of processing and computing, numeric instability is one of the challenges when simulations involve the modeling of elements that requires a high degree of synchronism, using discrete time steps, especially in interconnected multi-machine systems. The development and implementation methods and techniques to solve systems are of essential interest for the simultaneous progress of software and hardware for multi-core and parallel processing.

Future trends include the development of interface models to deal with data loss and delay issues. The delay among simulators can be reduced through the implementation of a communications fitting model. Algorithms could also be developed for the optimization of computation times. Future works include the improvement of synchronization among workstations and the solution of issues related to an effective communication interface among simulators. In that way, the use of HIL and PHIL integration schemes is currently an option with high potential to carry out the necessary integration for protection and execution of control testing.

On the other hand, the structuring of co-simulation schemes, where electrical and communications schemes are simulated simultaneously in real time, is another challenge in the field of simulation. This will provide the capability to preview the behavior of the system against not only electrical contingencies but also informatics such as cyber-attacks, saturation, and communications collapse. Approaches to the overall performance of electrical and communications systems are currently under development. Much study remains to be done to validate this kind of simulation and its field application.

Challenges to overcome involve the modeling and implementation of unconventional equipment and instruments for measurement, protection, and control as well the search for the necessary means for their effective integration in real-time simulations. Fig 7 shows the stages of a project where the mistakes must be detected and corrected, being so important the design stage. Fig 8 shows that the less work leads to an increase of the cost, because correcting the mistakes at later stages could double the initial budget. 
Eduardo Gómez, Luna, John Edwin Candelo Becerra and Eduardo Marlés Sáenz/

Journal of Engineering Science and Technology Review 11 (4) (2018) 204 - 215

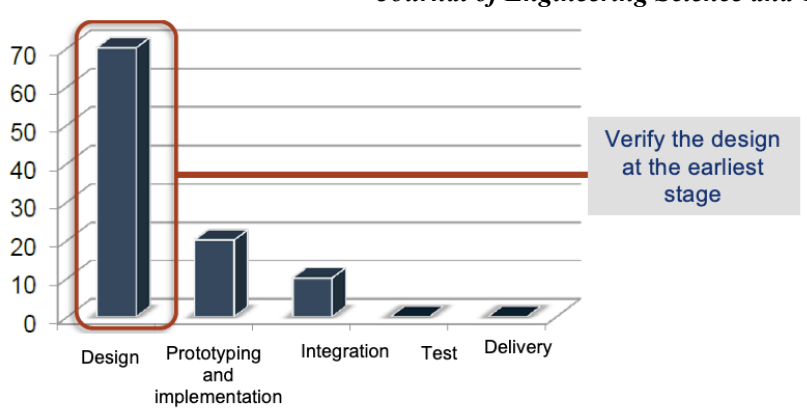

Fig. 7 Stages of the project and mistakes in percent [1].

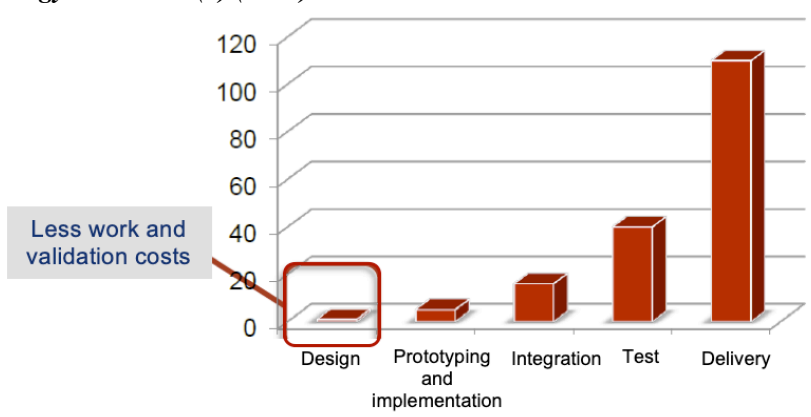

Fig. 8 Stages of the project and costs in percent [1].

Table 1. Classification of Technologies Sorted by Implementation Stages of Real-Time Simulation for Protection, control, and communications Applications and Testing.

\begin{tabular}{|c|c|c|c|}
\hline \multicolumn{3}{|c|}{ Real-time simulation implementation stages for protection, control, and communications testing } & \multirow{2}{*}{ References } \\
\hline Stage 1 & Stage 2 & Stage 3 & \\
\hline $\begin{array}{l}\text { OPAL-RT technologies based on } \\
\text { FPGA along with Matlab Simulink } \\
\text { Toolboxes }\end{array}$ & & & $\begin{array}{c}{[36],[38],[39],[42]-[47],[49]-[52],[56],} \\
{[69],[70],[72],[77]-[84]} \\
\end{array}$ \\
\hline QNX RT operating systems & & & {$[45],[50]-[52],[54],[77],[79],[83]$} \\
\hline $\begin{array}{l}\text { GNU/Linux and open-source-based } \\
\text { real-time simulation environments } \\
\text { and software }\end{array}$ & & & [37], [44], [52]-[54], [67], [77], [85]-[89] \\
\hline \multirow[t]{11}{*}{ State Space Nodal (SSN) solver } & & & $\begin{array}{c}\text { [18], [36], [38], [46], [49], [59], [60], [73], } \\
{[90]}\end{array}$ \\
\hline & $\begin{array}{l}\text { Use of parallel and multi-core } \\
\text { computing for high simulation } \\
\text { performance and precision } \\
\text { through OPAL-RT Technologies } \\
\text { and others. }\end{array}$ & & $\begin{array}{c}\text { [38], [40], [44], [45], [49], [50], [52], [59], } \\
{[60],[73],[74],[77],[87],[90]-[96]}\end{array}$ \\
\hline & $\begin{array}{l}\text { Data exchange through } \\
\text { high-speed } \mathrm{I} / \mathrm{O} \text { modules and } \\
\text { cards. }\end{array}$ & & $\begin{array}{c}{[41],[45],[46],[61]-[64],[67],[73],[75],} \\
{[79],[85],[89],[97]}\end{array}$ \\
\hline & $\begin{array}{l}\text { Use of high-performance and } \\
\text { speed network Internet } 2 \text { for data } \\
\text { transfer among simulators. }\end{array}$ & & [66] \\
\hline & 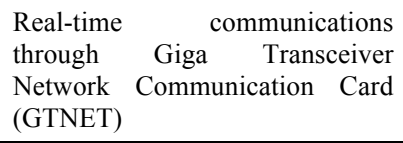 & & $\begin{array}{c}{[19],[40],[52],[54],[88],[57],[58],[65],} \\
{[66],[98]}\end{array}$ \\
\hline & $\begin{array}{l}\text { Interconnection of simulators } \\
\text { using the Ethernet TCP/IP } \\
\text { characteristic and inter-rack } \\
\text { communications (IRC) }\end{array}$ & & [3], [40],[52],[60], [57], [65], [66] \\
\hline & & $\begin{array}{l}\text { Hardware in the loop } \\
\text { (HIL) scheme using } \\
\text { OPAL-RT technologies, } \\
\text { RTDS, and others. } \\
\end{array}$ & $\begin{array}{c}{[36]-[39],[43]-[46],[51]-[53],[56],[62],} \\
{[63],[66],[69],[70],[72],[73],[78],} \\
{[83]-[85],[87]-[89],[99],[100]-[116]} \\
\end{array}$ \\
\hline & & $\begin{array}{l}\text { Use of power hardware in } \\
\text { the loop (PHIL) scheme }\end{array}$ & $\begin{array}{c}{[17],[49],[36],[81],[52],[67],[91],[112],} \\
{[114],[117]-[120]}\end{array}$ \\
\hline & & $\begin{array}{l}\text { Use of Intelligent } \\
\text { Electronic Devices } \\
\text { (IEDs) for measurement, } \\
\text { monitoring, and control. }\end{array}$ & $\begin{array}{c}{[19],[28],[49],[42],[43],[84],[54],[88],[61],} \\
{[75],[97],[98],[101],[71],[121]-[123]}\end{array}$ \\
\hline & & $\begin{array}{l}\text { Use of power amplifiers } \\
\text { to simulate power signals }\end{array}$ & $\begin{array}{c}{[17],[19],[49],[36],[81],[52],[89],[60],[75],} \\
{[97],[65],[57],[100],[117],[124]}\end{array}$ \\
\hline & & $\begin{array}{l}\text { Time-synchronized } \\
\text { injection tests using IEEE } \\
1588 \text { precision protocols } \\
\end{array}$ & {$[17],[61],[112],[125]$} \\
\hline $\begin{array}{lrr}\begin{array}{l}\text { Real-time } \\
\text { non-distributed }\end{array} & \text { distributed } & \text { and } \\
\text { RTDS technology } & & \text { using } \\
\end{array}$ & & & $\begin{array}{c}{[19],[40],} \\
{[41],[52],[54],[88],[85],[60],[90],[93],[75],} \\
{[97],[62]-[64],[65],[57],[58],[66],[98],} \\
{[100],[101],[111],[112],[121],[126]-[135]}\end{array}$ \\
\hline $\begin{array}{l}\text { Wide Area Monitoring, Protection, } \\
\text { and Control systems }\end{array}$ & & & $\begin{array}{c}\text { [36], [37], [40], [41], [49], [69],[115],[71], } \\
{[122],[124],[136],[137]}\end{array}$ \\
\hline $\begin{array}{l}\text { HVDC protection, control, and } \\
\text { communications systems through }\end{array}$ & & & [93] \\
\hline
\end{tabular}


Eduardo Gómez Luna, John Edwin Candelo Becerra and Eduardo Marlés Sáenz/

Journal of Engineering Science and Technology Review 11 (4) (2018) 204 - 215

\begin{tabular}{|c|c|c|c|}
\hline \multicolumn{3}{|c|}{ Real-time simulation implementation stages for protection, control, and communications testing } & \multirow{2}{*}{ References } \\
\hline Stage 1 & Stage 2 & Stage 3 & \\
\hline \multirow[t]{3}{*}{$\begin{array}{l}\text { SYMADYN and } \\
\text { platforms. }\end{array}$} & & & \\
\hline & & $\begin{array}{l}\text { Implementation } \begin{array}{l}\text { of } \\
\text { adaptive protection } \\
\text { schemes. }\end{array} \\
\end{array}$ & [49],[41],[43],[82],[101],[124],[138] \\
\hline & & $\begin{array}{l}\text { Use of National } \\
\text { Instruments technologies, } \\
\text { modules, and accessories } \\
\text { for signal acquisition and } \\
\text { processing. }\end{array}$ & {$[45],[79],[87],[90],[109],[113]$} \\
\hline \multirow[t]{4}{*}{$\begin{array}{l}\text { Central Protection, control, and } \\
\text { communications Systems (CPCS) }\end{array}$} & & & {$[54],[75],[97],[76]$} \\
\hline & $\begin{array}{l}\text { Real-time co-simulations to } \\
\text { simulate the interaction between } \\
\text { ICT and power systems }\end{array}$ & & {$[49],[58],[71],[122]$} \\
\hline & $\begin{array}{l}\text { Communications under protocol } \\
\text { IEC } 61850 \text { GOOSE and sample } \\
\text { values }\end{array}$ & & $\begin{array}{c}{[17],[19],[49],[36],[42],[43],[52],[54],[88],} \\
{[75],[97],[65],[57],[98],[71],[121],[123]}\end{array}$ \\
\hline & $\begin{array}{l}\text { Interface unit (IU) for } \\
\text { measurement and control }\end{array}$ & & {$[75],[97]$} \\
\hline \multirow[t]{5}{*}{ DSpace technologies } & & & {$[79],[52],[54],[67],[53],[110],[113]$} \\
\hline & $\begin{array}{l}\text { IEC } 61970 \text { standard application } \\
\text { for specification of automated } \\
\text { testing. }\end{array}$ & & {$[42],[71]$} \\
\hline & $\begin{array}{l}\text { Standards related to modeling, } \\
\text { connectivity, control, automation, } \\
\text { measurement, and management } \\
\text { of interconnected power sources. }\end{array}$ & & {$[139]-[150]$} \\
\hline & & $\begin{array}{l}\text { PMU and Synchrophasor } \\
\text { Vector Processors (SVPs) }\end{array}$ & $\begin{array}{c}{[17],[36],[40],[61],[69],[71],[72],[115]} \\
{[136],[137]}\end{array}$ \\
\hline & & CIL-CHIL & {$[42],[81],[41]$} \\
\hline $\begin{array}{l}\text { Power systems and ICT simulation } \\
\text { environment (EPOCHS) }\end{array}$ & & & {$[49],[71]$} \\
\hline Real-Time Hybrid simulator & & & {$[124],[128],[151]$} \\
\hline Matlab Real-Time Workshop & & & {$[44],[45],[59],[90],[68]$} \\
\hline $\begin{array}{l}\text { Real-Time extension of the Virtual } \\
\text { Test Bed (VTB-RT) }\end{array}$ & & & {$[52],[67],[113],[114],[105]$} \\
\hline \multirow[t]{5}{*}{ Speedgoat technology } & & & {$[151]$} \\
\hline & & $\begin{array}{l}\text { Network monitoring and } \\
\text { control based on real-time } \\
\text { wavelet transform. }\end{array}$ & {$[47]$} \\
\hline & $\begin{array}{l}\text { Time division multi-access } \\
\text { (TDMA) for precision in } \\
\text { simulation of power converters. }\end{array}$ & & {$[38]$} \\
\hline & $\begin{array}{l}\text { Communications using high-level } \\
\text { data connection (HDLC) } \\
\text { Gigabyte Ethernet and Aurora } \\
\text { protocol. }\end{array}$ & & {$[46],[38],[78]$} \\
\hline & $\begin{array}{l}\text { Use of distributed network } \\
\text { protocol } 3(\mathrm{DNP} 3)\end{array}$ & & $\begin{array}{c}{[17],[49],[36],[40],[50],[84],} \\
{[91],[61],[66],[58],[122]}\end{array}$ \\
\hline
\end{tabular}

\section{Conclusion}

This paper has conducted a review and analysis of the state-of-the-art and future trends of electrical grid protection, control, and communications testing using real-time simulation. The progress of technology in this matter and future implementations in the field of protection were presented to provide a better method to validate FAT-SAT commissioning for the protection, control, and communications of electrical substations.

A consolidation of different technologies and concepts related to the implementation stages of real-time protection, control, and communications testing is presented, with contributions from different authors that will allow future implementations and developments in this proposed matter.

This work presents a consolidated database with different solutions that allow the electrical grid protection, control, and communications testing to be optimized with the aim of reducing maintenance costs, unforeseen failures, inadequate coordination, incorrect designs, and demanding delivery times.

These are reduced using real-time simulation because it is 


\section{Eduardo Gómez, Luna, John Edwin Candelo Becerra and Eduardo Marlés Sáenz/}

\section{Journal of Engineering Science and Technology Review 11 (4) (2018) 204 - 215}

a tool that makes it possible to test IEDs, control equipment, and pilot plants with the modeled system, offering a high guarantee in its subsequent field execution without inconvenience.

Because unconventional renewable energy sources are increasingly being inserted in electrical power systems, protection coordination and system control are becoming more complex. Hence, it is necessary to use real-time simulation tools to analyze the performance of system components prior to their implementation in electrical grids. Therefore, this review work suggests that in modern electrical systems, real-time validation should always be done before field implementation with the aim of avoiding high costs due to inadequate planning.

Simulation and validation tests in real-time simulation laboratories are recommended, as these allow to implement models, systems and technological solutions for protection, control, and communications. These procedures are implemented to have reliable, safe, and accurate results, adding value to the traditional procedures required for taking early decisions and improving the operation of the power system. Besides, real-time simulation is recommended for designing, planning, testing, and validation of new protection, control, and communications strategies that are difficult to perform in the field.

\section{Acknowledgments}

The authors express their heartfelt thanks to the PTI S.A. Company for its support in the elaboration of this paper. They also thank COLCIENCIAS for its support for Project 54558,2016 , an approved project to access tax benefits, the Universidad del Valle and Universidad Nacional de Colombia, for its help provided us with this project.

This is an Open Access article distributed under the terms of the Creative Commons Attribution License

\section{References}

[1] J. Bélanger, P. Venne, and J.-N. Paquin, "The What, Where and Why of Real-Time Simulation," in Texas A \& $M$ Relay Conference, 1991, pp. 37-49.

[2] A. Kaddouri, B. Khodabakhchian, L.-A. Dessaint, R. Champagne, and L. Snider, "A new generation of simulation tools for electric drives and power electronics," in Proceedings of the IEEE 1999 International Conference on Power Electronics and Drive Systems. PEDS'99 (Cat. No.99TH8475), 1999, pp. 348-354 vol.1.

[3] R. Kuffel, J. Giesbrecht, T. Maguire, R. P. Wierckx, and P. Mclaren, "RTDS - A Fully Digital Power System Simulator Operating in Real Time," Int. Conf. Digit. power Syst. simulators, pp. 19-24, 1995.

[4] R. E. Crosbie, J. J. Zenor, D. Word, R. Bednar, and N. G. Hingorani, "A low-cost high-speed real-time simulator for ships power systems," in 2011 IEEE Electric Ship Technologies Symposium, 2011, pp. 102-105.

[5] L. Snider, J. Belanger, and G. Nanjundaiah, "Today’s power system simulation challenge: High-performance, scalable, upgradable and affordable COTS-based real-time digital simulators," in 2010 Joint International Conference on Power Electronics, Drives and Energy Systems \& 2010 Power India, 2010, pp. 1-10.

[6] C. A. Contreras and E. J. Hernández, "Sistemas de control en subestaciones de alta tensión del control convencional al control numérico," Cienc. e Ing., vol. 23, no. 2, pp. 15-22, 2002.

[7] N. A. Belyaev, N. V Korovkin, O. V Frolov, and V. S. Chudny, "Enhancing efficiency and performance of electric power systems by using Smart grid technology," Int. Symp. Electromagn. compatiblity, no. 1, pp. 846-849, 2013.

[8] A. Jokic, P. P. J. van den Bosch, A. Virag, W. H. A. Hendrix, L. Puglia, W. de Boer, R. Vujanic, and F. Nobel, "Reliability and efficiency at global level in power systems," in 2013 10th International Conference on the European Energy Market (EEM), 2013, pp. 1-8.

[9] M. Benidris, J. Mitra, and C. Singh, "Integrated Evaluation of Reliability and Stability of Power Systems," IEEE Trans. Power Syst., vol. 8950, no. c, pp. 1-1, 2017.

[10] J. A. Martinez, F. de Leon, A. Mehrizi-Sani, M. H. Nehrir, C. Wang, and V. Dinavahi, "Tools for Analysis and Design of Distributed Resources-Part II: Tools for Planning, Analysis and Design of Distribution Networks With Distributed Resources," IEEE Trans. Power Deliv., vol. 26, no. 3, pp. 1653-1662, Jul. 2011.

[11] Grupo Técnico Proyecto BID, "Parte I. Antecendetes y marco conceptual del análisis, evaluación y recomendaciones para la implementación de redes inteligentes en Colombia," Smart Grids Colombia Vision 2030, Bogotá, pp. 1-81, Apr-2016.

[12]F. Clavel, E. Savary, P. Angays, and A. Vieux-Melchior, "Integration of a New Standard: A Network Simulator of IEC 61850 Architectures for Electrical Substations," IEEE Ind. Appl. Mag., vol. 21, no. 1, pp. 41-48, Jan. 2015.
[13]A. M. Bouzid, P. Sicard, J.-N. Paquin, and A. Yamane, "A robust control strategy for parallel-connected distributed generation using real-time simulation," in 2016 IEEE 7th International Symposium on Power Electronics for Distributed Generation Systems (PEDG), 2016, pp. 1-8.

[14] J. A. Martinez, V. Dinavahi, M. H. Nehrir, and X. Guillaud, "Tools for Analysis and Design of Distributed Resources-Part IV: Future Trends," IEEE Trans. Power Deliv., vol. 26, no. 3, pp. 1671-1680, Jul. 2011.

[15] S. Tellez, D. Alvarez, W. Montano, C. Vargas, R. Cespedes, E. Parra, and J. Rosero, "National Laboratory of Smart Grids $(\mathrm{LAB}+\mathrm{i})$ at the National University of Colombia-Bogotá Campus," in 2014 IEEE PES Transmission \& Distribution Conference and Exposition - Latin America (PES T\&D-LA), 2014, pp. 1-6.

[16]K. S. Amitkumar and T. Ilamparithi, "Real-time studies on an improved modular stacked transmission and distribution system," in 2015 IEEE 16th Workshop on Control and Modeling for Power Electronics (COMPEL), 2015, no. I, pp. 1-8.

[17]P. Forsyth, O. Nzimako, C. Peters, and M. Moustafa, "Challenges of modeling electrical distribution networks in real-time," in 2015 International Symposium on Smart Electric Distribution Systems and Technologies (EDST), 2015, pp. 556-559.

[18]A. Yamane and S. Abourida, "Real-time simulation of distributed energy systems and microgrids," in 2015 International Conference on Sustainable Mobility Applications, Renewables and Technology (SMART), 2015, pp. 1-6.

[19]R. Kuffel, D. Ouellette, and P. Forsyth, "Real Time Simulation and Testing Using IEC 61850," 2010 Mod. Electr. Power Syst., pp. $1-8,2010$.

[20]Gang Li, Yunlong Dong, Jie Tian, Weihua Wang, Wei Li, and J. Belanger, "Factory acceptance test of a five-terminal MMC control and protection system using hardware-in-the-loop method," in 2015 IEEE Power \& Energy Society General Meeting, 2015, pp. 1-5.

[21] W. W. Weihua Wang, C. Dufour, W. L. Wei Li, and J. Bélanger, "A Real-time Simulator capable of studying dynamic insulation coordinate in a MMC-HVDC system," in 12th IET International Conference on AC and DC Power Transmission (ACDC 2016), 2016, p. 16 (4 .)-16 (4 .).

[22] A. Guillermo, "Subestaciones Electricas," in Notas de Clase, 2005, pp. $1-110$.

[23]C. F. Ramirez, Subestaciones de Alta y Extra Alta Tensión, 2da edició. 2003.

[24] Johan Hedberg, "Factory Acceptance Testing Guideline," AISTech - Iron Steel Technol. Conf. Proc., pp. 1-16, 2007.

[25] International Electrotechnical Commision, "IEC 61511: Functional safety - Safety instrumented systems for the process industry sector," International Standard. Geneva, pp. 1-175, 2016.

[26] Y.-S. Cho, C.-K. Lee, G. Jang, and T.-K. Kim, "Design and implementation of a real-time training environment for protective 
relay," Int. J. Electr. Power Energy Syst., vol. 32, no. 3, pp. 194-209, Mar. 2010.

[27]L. S. Barrantes Pineda and G. Robles Muñoz, "Diseño del Sistema de Protección y Control de Subestaciones Electricas," Carlos III de Madrid, 2011.

[28]A. B. S. M. Rayees, "Substation Automation Techniques and Future Trends," in 2007 Innovations in Information Technologies (IIT), 2007, pp. 412-416.

[29] Schnider-electric, "Integrated FAT Simulation ( IFS ): Off-Line EMCS simulation solution," PACiS EMCS SIMULATION, pp. $1-2,2016$.

[30] American Institute of Chemical Engineers, “Appendix H: Factory Acceptance Test Guidelines," in Guidelines for Safe Automation of Chemical Processes, Hoboken, NJ, USA: John Wiley \& Sons, Inc., 2010, pp. 402-407.

[31]P. Hallman, "Acceptance Testing \& Documentation to Support Validation,” Turnkey Modular Systems Inc., 2015.

[32]Add2 Enabling innovation, "Software-in-the-loop testing applications," $2017 . \quad$ [Online]. Available: http://www.add2.co.uk/applications/sil/. [Accessed: 29-Jun-2017].

[33]S. Werner, L. Masing, F. Lesniak, and J. Becker, "Software-in-the-Loop simulation of embedded control applications based on Virtual Platforms," in 2015 25th International Conference on Field Programmable Logic and Applications (FPL), 2015, pp. 1-8.

[34]M. Kelemen, T. Kelemenová, I. Virgala, L. Miková, and T. Lipták, "Rapid Control Prototyping of Embedded Systems Based on Microcontroller," Procedia Eng., vol. 96, pp. 215-220, 2014.

[35]Jing Feng, Hu Zhong, Guoqiang Ao, Junxi Wang, Hangbo Tang, Xiaojian Mao, and Bin Zhuo, "Principles and application of the real-time hardware-in-the-loop simulation platform based on multi-thread and CAN," in 2008 IEEE International Symposium on Industrial Electronics, 2008, pp. 2225-2230.

[36]C. Dufour and J. Bélanger, "On the Use of Real-Time Simulation Technology in Smart Grid Research and Development," IEEE Trans. Ind. Appl., vol. 50, no. 6, pp. 3963-3970, Nov. 2014.

[37]A. M. Kulkarni, K. Salunkhe, M. C. Chandorkar, S. P. Panda, and N. Sankaranarayanan, "Waveform-Relaxation based iterative real-time playback schemes for testing of wide area power system controllers," in IEEE PES General Meeting, 2010, pp. $1-8$.

[38]C. Lin, D. Liu, X. Wu, W. Wang, and W. Li, "Setup and Performance of a Combined Hardware-in-loop and Software-inloop Test for MMC-HVDC Control and Protection System," 2015 9th Int. Conf. Power Electron. ECCE Asia (ICPE-ECCE Asia), pp. 1333-1338, 2015.

[39]H. Rao, "Architecture of Nan'ao multi-terminal VSC-HVDC system and its multi-functional control," CSEE J. Power Energy Syst., vol. 1, no. 1, pp. 9-18, Mar. 2015.

[40]Li Jichen, Xue Feng, Fang Yongjie, Chang Kang, and S. Xiaofang, "Research on real-time simulation and communication of regional power grid based on RTDS and DNP 3.0," in 9th IET International Conference on Advances in Power System Control, Operation and Management (APSCOM 2012), 2012, pp. 22-22.

[41]H. Chou and K. L. Butler-Purry, "Real-time wide area power control studies using PXI and RTDS," in 2012 North American Power Symposium (NAPS), 2012, pp. 1-5.

[42]B. Bauernschmitt, D. Hilbrich, B. M. Keune, and C. Rehtanz, "Application of IEC 61850-6 and IEC 61970 Data Models for Automated Protection Test Specification," in 13th International Conference on Development in Power System Protection 2016 (DPSP), 2016, pp. 1-6.

[43]Z. Liu, H. K. Hoidalen, and M. M. Saha, "An intelligent coordinated protection and control strategy for distribution network with wind generation integration," CSEE J. Power Energy Syst., vol. 2, no. 4, pp. 23-30, Dec. 2016.

[44]S. K. Singh, B. P. Padhy, S. Chakrabarti, S. N. Singh, A. Kolwalkar, and S. M. Kelapure, "Development of Dynamic Test Cases in OPAL-RT Real-time Power System Simulator,” 2014 Eighteenth Natl. Power Syst. Conf., pp. 1-6, 2014.

[45] Wenxiao Ma, Yao Chen, and Dawei Yao, "PC-based real-time simulator and its application on testing of power plant auxiliary system control," in 2010 International Conference on Power System Technology, 2010, pp. 1-4.

[46] Yunlong Dong, Lei Pan, Defeng Qiu, Jie Tian, Weihua Wang, and Wei Li, "Hardware-in-the-loop simulation and test of a control and protection system for MMC-based UPFC," in 2016 IEEE Power and Energy Society General Meeting (PESGM), 2016, pp.

\section{$1-5$.}

[47] S. Singh, B. Jain, and S. Jain, "Wavelet based real-time power quality monitoring," in 2016 IEEE Canadian Conference on Electrical and Computer Engineering (CCECE), 2016, pp. 1-6.

[48]C. S. Edrington, M. Steurer, J. Langston, T. El-Mezyani, and K. Schoder, "Role of Power Hardware in the Loop in Modeling and Simulation for Experimentation in Power and Energy Systems," Proc. IEEE, vol. 103, no. 12, pp. 2401-2409, Dec. 2015.

[49]C. Rehtanz and X. Guillaud, "Real-time and co-simulations for the development of power system monitoring, control and protection," in 2016 Power Systems Computation Conference (PSCC), 2016, pp. 1-20.

[50]Lin-Yu Lu, Jian-Hong Liu, Chia-Chi Chu, Yu-Chi Wu, and Po-Tai Cheng, "Real-time simulations of a laboratory-scale micro-grid system in Taiwan," in 2012 IEEE 13th Workshop on Control and Modeling for Power Electronics (COMPEL), 2012, pp. 1-8.

[51]O. Crăciun, A. Florescu, I. Munteanu, A. I. Bratcu, S. Bacha, and D. Radu, "Hardware-in-the-loop simulation applied to protection devices testing," Int. J. Electr. Power Energy Syst., vol. 54, pp. 55-64, Jan. 2014.

[52] M. D. Omar Faruque, T. Strasser, G. Lauss, V. Jalili-Marandi, P. Forsyth, C. Dufour, V. Dinavahi, A. Monti, P. Kotsampopoulos, J. a. Martinez, K. Strunz, M. Saeedifard, Xiaoyu Wang, D. Shearer, and M. Paolone, "Real-Time Simulation Technologies for Power Systems Design, Testing, and Analysis," IEEE Power Energy Technol. Syst. J., vol. 2, no. 2, pp. 63-73, Jun. 2015.

[53]H.-Y. Kim, N.-J. Lee, D.-C. Lee, and C.-G. Kang, "Hardware-in-the-Loop Simulation for a Wheel Slide Protection System of a Railway Train," IFAC Proc. Vol., vol. 47, no. 3, pp. 12134-12139, 2014.

[54]A. Umair, A. Nikander, and P. Järventausta, "Simulation Environment for Centralized Protection and Control applying dSPACE and RTDS with IEC 61850 9-2 Communication," 2016 IEEE PES Innov. Smart Grid Technol. Conf. Eur., pp. 1-5, 2016.

[55]A. Yamane, S. Abourida, Y. Bouzid, and F. Tempez, "Real-Time Simulation of Distributed Energy Systems and Microgrids," IFAC-PapersOnLine, vol. 49, no. 27, pp. 183-187, 2016.

[56] Weihua Wang, Jin Zhu, Wei Li, and J. Belanger, "Analysis and hardware-in-the-loop simulation of a pole-to-pole DC fault in MMC-based HVDC systems," in 2015 IEEE 13th Brazilian Power Electronics Conference and 1st Southern Power Electronics Conference (COBEP/SPEC), 2015, pp. 1-5.

[57]P. Forsyth and R. Kuffel, "Utility applications of a RTDS ( Simulator," 8th Int. Power Eng. Conf. (IPEC 2007), pp. 112-117, 2007.

[58] M. Manbachi, A. Sadu, H. Farhangi, A. Monti, A. Palizban, F. Ponci, and S. Arzanpour, "Impact of EV penetration on Volt-VAR Optimization of distribution networks using real-time co-simulation monitoring platform," Appl. Energy, vol. 169, pp. 28-39, May 2016.

[59]C. Dufour, S. Cense, V. Jalili-marandi, and J. Bélanger, "Review of state-of-the-art solver solutions for HIL simulation of power systems, power electronic and motor drives Keywords CPU vs . FPGA HIL overview HIL methods for power systems, motor drives and power electronic," 2013 15th Eur. Conf. Power Electron. Appl., pp. 1-12, 2013.

[60] P. Forsyth, T. Maguire, and R. Kuffel, "Real time digital simulation for control and protection system testing," in 2004 IEEE 35th Annual Power Electronics Specialists Conference (IEEE Cat. No.04CH37551), 2004, vol. 1, pp. 329-335.

[61]E. O. Schweitzer and D. E. Whitehead, "Real-Time Power System Control Using Synchrophasors," in 2008 61st Annual Conference for Protective Relay Engineers, 2008, pp. 78-88.

[62]P. Mitra, J. Hanning, J. Kohlstrom, T. Larsson, and J. Danielsson, "DC grid system behavior: A real-time case study," in 2015 IEEE Power \& Energy Society General Meeting, 2015, pp. 1-5.

[63]P. Mitra, C. Wikstrom, T. Larsson, and N. Johannesson, "First real-time implementation of DC grid protection strategy," in 11th IET International Conference on $A C$ and $D C$ Power Transmission, 2015, p. 060 (8 .)-060 (8 .).

[64]Y. Cui, Y. Yu, and Q. Guo, "Development and application of real-time digital simulation platform for URV DC and AC grid," in 2014 China International Conference on Electricity Distribution (CICED), 2014, no. CICED, pp. 324-328.

[65]D. X. Du, Z. Q. Bo, Z. X. Zhou, A. Perks, L. Denning, and B. Smith, "An Advanced Real Time Digital Simulator Based Test System for Protection Relays," in Proceedings of the 41st International Universities Power Engineering Conference, 2006, vol. 3, pp. 851-855. 


\section{Eduardo Gómez, Luna, John Edwin Candelo Becerra and Eduardo Marlés Sáenz/}

\section{Journal of Engineering Science and Technology Review 11 (4) (2018) 204 - 215}

[66]K. G. Ravikumar, N. N. Schulz, and A. K. Srivastava, "Distributed simulation of power systems using real-time digital simulator," in 2009 IEEE/PES Power Systems Conference and Exposition, 2009, pp. 1-6.

[67]X. Wu, H. Figueroa, and A. Monti, "Testing of digital controllers using real-time hardware in the loop simulation," in 2004 IEEE 35th Annual Power Electronics Specialists Conference (IEEE Cat. No.04CH37551), 2004, vol. 5, pp. 3622-3627.

[68]A. J. Roscoe, S. M. Blair, and G. M. Burt, "Benchmarking and optimisation of Simulink code using Real-Time Workshop and Embedded Coder for inverter and microgrid control applications," 2009 44th Int. Univ. Power Eng. Conf., pp. 1-5, 2009.

[69]E. Rebello, L. Vanfretti, and M. Shoaib Almas, "PMU-based real-time damping control system software and hardware architecture synthesis and evaluation," in 2015 IEEE Power \& Energy Society General Meeting, 2015, pp. 1-5.

[70] S. Dennetière, H. Saad, B. Clerc, and J. Mahseredjian, "Setup and performances of the real-time simulation platform connected to the INELFE control system," Electr. Power Syst. Res., vol. 138, pp. $180-187$, Sep. 2016.

[71] S. C. Muller, H. Georg, C. Rehtanz, and C. Wietfeld, "Hybrid simulation of power systems and ICT for real-time applications," in 2012 3rd IEEE PES Innovative Smart Grid Technologies Europe (ISGT Europe), 2012, pp. 1-7.

[72]H. Hooshyar, F. Mahmood, L. Vanfretti, and M. Baudette, "Specification, implementation, and hardware-in-the-loop real-time simulation of an active distribution grid," Sustain. Energy, Grids Networks, vol. 3, pp. 36-51, Sep. 2015.

[73] Qingping Wang, Changnian Lin, Yong Chang, Jingke Wu, Ping Zhang, Bin Feng, and Shuyang Gu, "Study of HVDC hardware-in-loop training simulator," in 2010 International Conference on Power System Technology, 2010, pp. 1-6.

[74]D. Paradis, "Real-Time Simulation of Modular Multilevel Converters," University of Toronto, 2013

[75]Z. Q. Bo, A. Klimek, Y. L. Ren, and J. H. He, “A Real Time Digital Simulation System for Testing of Integrated Protection Schemes," in 2008 Joint International Conference on Power System Technology and IEEE Power India Conference, 2008, pp. $1-5$.

[76]M. Xu, T. Meng, G. Zou, J. Zhang, X. Lin, and J. Yang, "A centralized protection and control scheme for microgrid," in 2015 IEEE PES Asia-Pacific Power and Energy Engineering Conference (APPEEC), 2015, pp. 1-5.

[77]C. Dufour and J. Belanger, "A PC-Based Real-Time Parallel Simulator of Electric Systems and Drives," in Parallel Computing in Electrical Engineering, International Conference on, 2004, pp. 105-113.

[78]Z. Zhu, X. Li, H. Rao, W. Wang, and W. Li, "Testing a Complete Control and Protection System for Multi-terminal MMC HVDC Links Using Hardware-in-the-loop Simulation," IECON 2014 40th Annu. Conf. IEEE Ind. Electron. Soc., pp. 4402-4408, 2014.

[79] W. Tu, G. Luo, S. Ma, and X. Fang, "Design of Permanent Magnet Synchronous Motor real-time simulation control system," in 2013 IEEE International Conference on Information and Automation (ICIA), 2013, no. August, pp. 1124-1129.

[80] T. Hu, F. Li, C. Liu, L. Bang, Y. Zhu, P. Dong, C. Wei, and L. Li, "Real-Time Simulation and Parameter Optimization for SVC Control Tragedy of XiZ an g Grid," 2014 China Int. Conf. Electr. Distrib., no. CICED, pp. 1507-1512, 2014.

[81] P. C. Kotsampopoulos, F. Lehfuss, G. F. Lauss, B. Bletterie, and N. D. Hatziargyriou, "The Limitations of Digital Simulation and the Advantages of PHIL Testing in Studying Distributed Generation Provision of Ancillary Services," IEEE Trans. Ind. Electron., vol. 62, no. 9, pp. 5502-5515, Sep. 2015.

[82]E. C. Piesciorovsky and N. N. Schulz, "Comparison of non-real-time and real-time simulators with relays in-the-loop for adaptive overcurrent protection," Electr. Power Syst. Res., vol. 143, pp. 657-668, Feb. 2017.

[83]X. Chen, P. Fu, L. Huang, G. Gao, and S. He, "Hardware-in-the-loop simulation of the EAST PF converter for PF control system upgrade," Fusion Eng. Des., vol. 112, pp. 57-66, Nov. 2016.

[84] S. Poudel, Z. Ni, and N. Malla, "Real-time cyber physical system testbed for power system security and control," Int. J. Electr. Power Energy Syst., vol. 90, pp. 124-133, Sep. 2017.

[85]M. Chaitanya, G. Gurrala, and G. Narayanan, "Real-time simulation of an Islanded microgrid using educational Miniature Full Spectrum Simulator," in 2016 National Power Systems
Conference (NPSC), 2016, no. 1, pp. 1-6.

[86] R. P. Mehta, M. B. Patil, and M. Chandorkar, "Laboratory Tools for DSP based Real-time Simulation," 2011 Annu. IEEE India Conf.,pp. 1-8, 2011.

[87]R. Razzaghi, M. Paolone, and F. Rachidi, "A general purpose FPGA-based real-time simulator for power systems applications," in IEEE PES ISGT Europe 2013, 2013, pp. 1-5.

[88] P. Jamborsalamati, A. Sadu, F. Ponci, and A. Monti, "A flexible HiL testing platform for performance evaluation of IEC 61850-based protection schemes," in 2016 IEEE Power and Energy Society General Meeting (PESGM), 2016, pp. 1-5.

[89] I. F. Galindo Garcia, S. Rodriguez Lozano, and O. P. Hernandez De La O, "Development of a Real Time Simulator to Test Load and Speed Control Systems of Hydroelectric Power Plants," in 2009 International Conference on Electrical, Communications, and Computers, 2009, pp. 250-255.

[90]A. Saran, S. K. Palla, A. K. Srivastava, and N. N. Schulz, "Real time power system simulation using RTDS and NI PXI," in 2008 40th North American Power Symposium, 2008, pp. 1-6.

[91]K. Schoder, J. Langston, and M. Steurer, "Commissioning of MW-scale Power Hardware-in-the-Loop interfaces for experiments with AC/DC Converters," in IECON 2013 - 39th Annual Conference of the IEEE Industrial Electronics Society, 2013, pp. 5364-5367.

[92]A. J. Flueck, "High-Fidelity, Faster than Real-Time Dynamics Simulation," 2014 IEEE PES Gen. Meet.|Conf. Expo., p. 1, 2014.

[93] Y. P. Li, D. G. Wang, A. P. Hu, S. Member, W. Wang, and Z. Q. Yao, "Real-time Simulation Study on HVDC Control and Protection," 2010 Int. Conf. Power Syst. Technol., no. 1706, pp. $1-6,2010$.

[94]P. Singh, "Real-time modeling and simulation of distribution feeder and distributd resources," Colorado State University, 2015.

[95]A. Jain, "Synchronized Real-Time Simulation of Distributed Networked Controls for a Power System Case Study," Colorado State University, 2013.

[96] O. Raipala, "Real time simulation of active distribution network," Tampere University of Technologic, 2009.

[97]D. Du, H. Wang, Z. Bo, Z. Zhou, X. Dong, B. R. J. Caunce, and A. Klimek, "Design of a Real Time Digital Simulation System for Test of New Protection Schemes," in 2006 International Conference on Power System Technology, 2006, pp. 1-6.

[98]L. E. da Silva and D. V. Coury, "A new methodology for real-time detection of attacks in IEC 61850-based systems," Electr. Power Syst. Res., vol. 143, pp. 825-833, Feb. 2017.

[99]E. C. Piesciorovsky and N. N. Schulz, "Comparison of Programmable Logic and Setting Group Methods for adaptive overcurrent protection in microgrids," Electr. Power Syst. Res., vol. 151, pp. 273-282, 2017.

[100] D. Kong, A. Taylor, Y. Xue, and X.-P. Zhang, "A New Independent Methodology for Protection and Control Coordination Studies Using Real Time Digital Simulation," in 13th International Conference on Development in Power System Protection 2016 (DPSP), 2016, pp. 1-6.

[101] V. A. Papaspiliotopoulos, G. N. Korres, V. A. Kleftakis, and N. D. Hatziargyriou, "Hardware-In-the-Loop Design and Optimal Setting of Adaptive Protection Schemes for Distribution Systems With Distributed Generation," IEEE Trans. Power Deliv., vol. 32 no. 1, pp. 393-400, Feb. 2017.

[102] L. Chang, Z. Qi, L. Zhiyu, G. Jin, and H. S. Rong, "Building method for electric drive system hardware-in-the-loop simulation device," CN102012674 A, 2011.

[103] Y. Pingping, W. Zhipeng, and W. Jia, "Flexible direct current power transmission semi-physical simulation system based on modularization multi-level current converter," CN103792854 B, 2014.

[104] N. Bruski, R. G. Boerger, H. Krisp, R. Leinfellner, E. Miller, J. Richert, and T. Woelfer, "Method for Testing an Electronic Control System," US7933734 B2, 2008.

[105] B. Lu, "The real-time extension of the virtual test bed: A multisolver hard real-time hardware-in-the-loop simulation environment," University of South Carolina, 2003.

[106] Y. J. Lee, “The Real-Time Implementation of Hardware-In-the Loop Systems on Different RTOS Platforms," Georgia Institute of Technology, 2003.

[107] C. Palhad, "An Investigation Into The Use Of Real-Time Simulation And Hardware-In-The-Loop Techniques For Studying The Dynamic Performance Of Adjustable Speed Drives Under Fault Conditions," University of KwaZulu-Natal, 2015. 


\section{Eduardo Gómez, Luna, John Edwin Candelo Becerra and Eduardo Marlés Sáenz/}

\section{Journal of Engineering Science and Technology Review 11 (4) (2018) 204 - 215}

[108] B. Lundstrom, "An Advanced Platform for Development and Evaluation of Grid Interconnection Systems Using Hardware-in-the-Loop," Colorado School of Mines, 2013.

[109] J. Wu, Y. Cheng, A. Srivastava, N. Schulz, and H. Ginn, "Hardware in the Loop Test for Power System Modeling and Simulation," in 2006 IEEE PES Power Systems Conference and Exposition, 2006, pp. 1892-1897.

[110] J. V. Barreras, M. Swierczynski, E. Schaltz, S. J. Andreasen, C. Fleischer, D. Uwe Sauer, and A. E. Christensen, "Functional analysis of Battery Management Systems using multi-cell HIL simulator," in 2015 Tenth International Conference on Ecological Vehicles and Renewable Energies (EVER), 2015, pp. $1-10$.

[111] A. H. Etemadi and R. Iravani, "Overcurrent and Overload Protection of Directly Voltage-Controlled Distributed Resources in a Microgrid," IEEE Trans. Ind. Electron., vol. 60, no. 12, pp. 5629-5638, Dec. 2013

[112] P. Crolla, A. J. Roscoe, A. Dysko, and G. M. Burt, "Methodology for testing loss of mains detection algorithms for microgrids and distributed generation using real-time power hardware-in-the-loop based technique," in 8th International Conference on Power Electronics - ECCE Asia, 2011, pp. 833-838.

[113] B. Lu, X. Wu, H. Figueroa, and A. Monti, "A Low-Cost Real-Time Hardware-in-the-Loop Testing Approach of Power Electronics Controls," IEEE Trans. Ind. Electron., vol. 54, no. 2 , pp. 919-931, Apr. 2007.

[114] H. Figueroa, J. Bastos, A. Monti, and R. Dougal, "A Modular Real-Time Simulation Platform Based on the Virtual Test Bed," in 2006 IEEE International Symposium on Industrial Electronics, 2006, vol. 2, pp. 1537-1541.

[115] R. Kuffel, P. Forsyth, and C. Peters, "The Role and Importance of Real Time Digital Simulation in the Development and Testing of Power System Control and Protection Equipment," IFAC-PapersOnLine, vol. 49, no. 27, pp. 178-182, 2016.

[116] J. C. Deal, R. Martinez, T. Haynes, W. G. Whimpenny, T. N. Nguyen, S. A. Burgan, K. McNeill, and A. Needham, "Interfacing real and virtual networks in hardware-in-the-loop (HITL) simulations," US 20110142057 A1, 2011.

[117] B. Lundstrom, B. Mather, M. Shirazi, and M. Coddington, "Implementation and validation of advanced unintentional islanding testing using power hardware-in-the-loop (PHIL) simulation," in 2013 IEEE 39th Photovoltaic Specialists Conference (PVSC), 2013, pp. 3141-3146.

[118] S. Jin, L. Pang, L. Wan, J. Huang, and H. Jiang, "Method and apparatus for performing real-time, in-the-field switching-order simulation for an electric power system," US 20130311161 A1, 2015.

[119] A. Monti and S. D'Arco, "Systems and Methods for Power Hardware in the Loop Testing," US7979223 B2, 2008.

120] R. Hong, T. Jie, L. Xiaolin, L. Yan, L. Gang, D. Yunlong, and W. $\mathrm{Ke}$, "Closed loop test system of flexible direct current transmission control protection system," CN103439967 A, 2013.

121] P. Jamborsalamati, A. Sadu, F. Ponci, and A. Monti, "Design, implementation and real-time testing of an IEC 61850 based FLISR algorithm for smart distribution grids," in 2015 IEEE International Workshop on Applied Measurements for Power Systems (AMPS), 2015, pp. 1-6.

[122] N. Dorsch, H. Georg, and C. Wietfeld, "Analysing the real-time-capability of wide area communication in smart grids," in 2014 IEEE Conference on Computer Communications Workshops (INFOCOM WKSHPS), 2014, pp. 682-687.

[123] E. Perez and J. de la Ree, "Development of a real time simulator based on ATP-EMTP and sampled values of IEC61850-9-2," Int. J. Electr. Power Energy Syst., vol. 83, pp. 594-600, Dec. 2016.

[124] A. Prokhorov, Y. Borovikov, and M. Andreev, "Application of hybrid real-time power system simulator for setting up and close loop testing of protection and control equipment," in $20127 \mathrm{th}$ International Forum on Strategic Technology (IFOST), 2012, pp. $1-4$.

[125] F. Fink, J. Köppel, and T. Hensler, "Effective commissioning of bus bar protection systems using a dynamic simulation in the field," in 13th International Conference on Development in Power System Protection 2016 (DPSP), 2016, pp. 1-6.

[126] F. Lei, W. Fenqing, H. Yuqiang, and Y. Jia, "Test and simulation research of security and stability control technology of UHVDC based on real-time digital simulation," in 2016 China International Conference on Electricity Distribution (CICED), 2016, no. CICED, pp. 1-6.
[127] M. Hu, S. Member, C. Fu, J. S. Wang, S. Member, H. Rao, and H. B. Liu, "Real Time Digital Simulation of the Parallel Multi-terminal HVDe transmission System," 2012 IEEE Int. Conf. Power Syst. Technol., pp. 1-5, 2012.

[128] Y. Hu, W. Wu, and B. Zhang, "An RTDS-TSA Hybrid Real-Time Transient Simulation Platform with Refined Frequency Dependent Network Equivalent Techniques,' IFAC-PapersOnLine, vol. 48, no. 30, pp. 215-220, 2015.

[129] X. Ruilin, C. Tao, Z. Xiaojun, W. Lingyun, and L. Zhisheng, "Function test platform and method for transformer relaying protection device based on real time digital system (RTDS)," CN102200560 B, 2011

[130] T. Yonghong, L. Min, X. Lin, Z. Bei, L. Xing, D. Huikai, and F. Hong, "Testing platform for regional power grid automatic voltage control (AVC) system function tests based on real time digital simulator (RTDS) and construction method of testing platform," CN102981500 B, 2013.

[131] Z. Xiaojun, X. Ruilin, C. Tao, W. Y. A, and L. Junjie, "RTDS-based platform and method for function test of circuit protective relaying device," CN102253292 B, 2011.

[132] C. Yong and G. Qiang, "Direct-current control protection simulator based on real time digital system (RTDS)," CN203101860 U, 2013.

[133] W. Jun, C. Donghai, Y. Haojun, D. Peking, D. Huikai, X. Qiao, and L. Strong, "RTDS-based (real-time digital simulator) arc protector function test platform," CN103235218 B, 2013.

[134] S. Bing, Z. Jian, Z. Ping, and Z. Desheng, "Real time digital simulator (RTDS) testing method of fault current limiter,' CN102998571 B, 2013

[135] D. Cai-bo, F. Rui-xiang, X. Zai-de, X. Hong-xia, P. Ben-ren, and X. Jun-jie, "Closed loop simulation testing method of low-voltage active filter controller based on RTDS," CN103760888 A, 2014.

[136] M. A. Saad, A. H. Eltom, G. L. Kobet, and R. Ahmed, "Performance comparison between Dual-Blinder and Phasor-Based Out-of-Step detection functions using hardware-in-the loop simulation," in 2015 IEEE Industry Applications Society Annual Meeting, 2015, pp. 1-8.

[137] X. Du and P. Crossley, "Study on a real time model predictive based power system SIPS," in 2013 IEEE Grenoble Conference, 2013, pp. 1-5.

[138] C. Hussain, Syed Zakir (Hillsborough, "Real-time adaptive circuit simulation," US 8195439, 2012.

[139] International Electrotechnical Commision, "IEC 61501: Voltage sourced converter (VSC) valves for high-voltage direct current (HVDC) power transmission - Electrical testing." Geneva, pp. $1-83,2009$.

[140] International Electrotechnical Commision, "IEC 61850 Communication networks and systems for power utility automation." Geneva, pp. 1-4378, 2016.

[141] IEEE Computer Society, "IEEE Std 802.3: Standard for Ethernet," no. December. IEEE-SA Standards Board, New York, pp. 1-4017, 2015.

[142] IEEE, "IEEE 1547: Standard for Interconnecting Distributed Resources with Electric Power Systems," no. June. IEEE-SA Standards Board, New York, pp. 1-27, 2003.

[143] International Electrotechnical Commision, "IEC 61158: Digital data communications for measurement and control - Fieldbus for use in industrial control systems." Geneva, pp. 1-325, 2003.

[144] International Electrotechnical Commision, "IEC 61970: Energy management system application program interface (EMS-API)." Geneva, pp. 1-174, 2003.

[145] International Electrotechnical Commision, "IEC 62351: Security Standards for the Power System Information Infrastructure.” IEC TC57 WG15 Security Standards, 2012.

[146] IEEE Instrumentation and Measurement Society, "IEEE Std 1588 Standard for a Precision Clock Synchronization Protocol for Networked Measurement and Control Systems," no. July. IEEE-SA Standards Board, New York, pp. 1-269, 2008.

[147] IEEE Computer Society, "IEEE Std 1666: Standard for Standard SystemC® Language Reference Manual,” no. January. IEEE-SA Standards Board, New York, pp. 1-638, 2011.

[148] UL, "UL 1741: Standard for Inverters, Converters, Controllers and Interconnection System Equipment for Use With Distributed Energy Resources.” 2010.

[149] IEEE Power \& Energy Society, "IEEE Std C37.118: Standard fo Synchrophasor Measurements for Power Systems," no. December. IEEE-SA Standards Board, New York, 2011

[150] IEEE Computer Society, "IEEE 1516: Standard for Modeling and 
Eduardo Gómez Luna, John Edwin Candelo Becerra and Eduardo Marlés Sáenz/

Journal of Engineering Science and Technology Review 11 (4) (2018) 204 - 215

Simulation (M\&S) High Level Architecture (HLA)-Framework and Rules.” IEEE-SA Standards Board, New York, pp. 1-38, 2010.

[151] F. Lin, A. Maghareh, S. J. Dyke, and X. Lu, "Experimental implementation of predictive indicators for configuring a real-time hybrid simulation," Eng. Struct., vol. 101, pp. 427-438, Oct. 2015. 